\title{
Voluntary Induced Abortion in Cameroon: Prevalence, Reasons, and Complications
}

\author{
Jean Dupont Kemfang Ngowa1,2*, Humphry Tatah Neng², Joel Fokom Domgue², \\ Christiane Jivir Nsahlai ${ }^{2}$, Jean Marie Kasia ${ }^{1,2}$ \\ ${ }^{1}$ Obstetrics and Gynecology Unit, Yaoundé General Hospital, Yaoundé, Cameroon \\ ${ }^{2}$ Department of Obstetrics and Gynecology, Faculty of Medicine and Biomedical Sciences, \\ University of Yaoundé I, Yaoundé, Cameroon \\ Email: *jdkemfang@yahoo.fr
}

Received 21 July 2015; accepted 22 August 2015; published 25 August 2015

Copyright (C) 2015 by authors and Scientific Research Publishing Inc.

This work is licensed under the Creative Commons Attribution International License (CC BY). http://creativecommons.org/licenses/by/4.0/

(c) (;) Open Access

\section{Abstract}

Background: In Cameroon, induced abortion is permitted when a woman's life is at risk, to preserve her physical and mental health and on the grounds of rape or incest. Objectives: The aim of this study was to determine the prevalence, reasons and complications of voluntary induced abortion among women attending the obstetrics and gynecology services in an urban area, Yaoundé and in a rural area, Wum in Cameroon. Methods: We carried out a cross sectional study, with 509 women recruited between August 1, 2011 and December 31, 2011 in three health facilities in Cameroon. We appreciated the frequency, complications and reasons for Voluntary induced abortions. Results: The prevalence of voluntary induced abortion was $26.3 \%(134 / 509)$ globally; $25.6 \%$ $(65 / 254)$ in urban area and $27.1 \%(69 / 255)$ in rural area. One hundred and eleven $(83 \%)$ cases of induced abortions were carried out in a health structure and $23(17 \%)$ cases in private homes. Medical doctors and nurses were the most frequent abortion providers in both urban (84.7\%) as well as rural setting $(\mathbf{7 7 . 2 \% )}$. The three main reasons for induced abortion were to pursue their studies $(34.3 \%)$, not yet married $(22.6 \%)$ and fear of parents $(13.9 \%)$. Complications were reported by $20 \%(27 / 134)$ of respondents who had carried out voluntary induced abortion. Excessive bleeding was the most reported complication (70.4\%). Conclusion: Despite its illegality in Cameroon, the prevalence of voluntary induced abortion was high in this study.

\section{Keywords}

Induced Abortion, Unsafe Abortion, Voluntary Abortion, Voluntary Induced Abortion

\footnotetext{
${ }^{*}$ Corresponding author.
}

How to cite this paper: Ngowa, J.D.K., Neng, H.T., Domgue, J.F., Nsahlai, C.J. and Kasia, J.M. (2015) Voluntary Induced Abortion in Cameroon: Prevalence, Reasons, and Complications. Open Journal of Obstetrics and Gynecology, 5, 475-480. 


\section{Introduction}

Induced abortion is a practice that has been going on all over the world for a very long time and, in most places, it is shrouded in secrecy, which makes it difficult to determine the exact incidence of the condition. Recent estimation gives an overall figure of around 30 million induced abortions annually in the developing world, with Africa having about 3.4 million [1]. In Cameroon, induced abortion is permitted when a woman's life is at risk, to preserve her physical and mental health and on grounds of rape or incest [2]. Thus, Illegal abortions are punishable by a fine of up to two million CFA (about 3000 Euros) plus jail term of up to five years for the abortionist, one year for the woman herself and two years for anyone supplying drugs or instruments to induce abortion [2] [3].

Unintended pregnancy is a problem that may never be fully resolved, and women who do not wish to continue a pregnancy will often seek termination by any means, regardless of its safety [4]. Thus, clandestine abortion services offered by lay abortionists, trained midwives, and so-called native doctors, unknown to the public health service, are in fact common [1] [5].

Unsafe abortion is defined by the World Health Organization as a procedure for terminating an unwanted pregnancy either by persons lacking the necessary skills or in an environment lacking the minimal medical standards or both [6].

The immediate complications of unsafe abortion are hemorrhage and sepsis. Both may require operative intervention, ranging from evacuation of the uterus to laparotomy, colostomy, bowel resection, and hysterectomy [7]. There have been studies that look into the reasons behind abortions [8] [9]. Many tend to suggest that increased access to and use of modern contraceptive methods will result in a decrease in induced abortions in the developing world. However, it has been shown that despite the fact that contraceptive prevalence rates have increased dramatically in the developing world in the past 30 years, induced abortion rates continue to be very high [8] [10]-[12].

This study aimed to determine the prevalence, reasons and complications of voluntary induced abortion among women attending the obstetrics and gynecology service at the Gynaeco-obstetrics and Pediatric Hospital of Yaoundé and Yaoundé General Hospital(both in an urban area), and Wum district hospital in a rural area in Cameroon, central Africa.

\section{Methods}

This was a cross sectional study carried out at three public health facilities, two in Yaoundé, an urban area (Yaoundé Gynecology Obstetrics and pediatric Hospital and Yaoundé General Hospital) and one in Wum, a rural area (Wum District Hospital) in Cameroon. The study period was between August 1, 2011 and December 31, 2011. The study population was all women attending the Obstetrics and gynecology service in these three hospitals during the study period. We included women aged 15 to 49 years who consented to participate to this study. Authorization to conduct the study was obtained from the National Ethical Committee of Cameroon. The main study tool was a questionnaire designed by the study team. The questionnaire had 25 questions and was administered by two trained researchers who were senior obstetrics and gynecology residents. The questionnaire was anonymous and included closed and open-ended questions. Patients eligible to be interviewed were identified on a daily basis from the ward admission records. The pilot study of the questionnaire was performed on fifty women. The questionnaire examined socio-demographic characteristics of the subjects, previous history of induced abortions, contraceptive knowledge, contraceptive use, the reasons, place, providers, methods and complications of the abortions. A list of complications potentially related to abortion, including heavy bleeding, infection, menstrual disorders, chronic pelvic pain, blood transfusion, infertility, and hysterectomy were asked via questionnaire. All analyses were performed with SPSS for Windows 16.0 (SPSS Inc., Chicago, IL). Descriptive statistics were used for categorizing the sample by variables and calculating the means and standard deviations. A p value of less than 0.05 was considered as statistically significant.

\section{Results}

During the period of study, a total of 509 women were included, 255 from rural setting at Wum and 254 from urban setting at Yaoundé. Of the 509 respondents, 134 (26.3\%) admitted having had a voluntary induced abortion at least once, 65 (25.6\%) in the urban setting and 69 (27.1\%) in rural area. Among those with a history of 
induced abortion, 38 (29.3\%) had undertaken more than 01 induced abortion. The 20 - 29 years age group was the most represented (55.2\%).

Table 1 shows the socio-demographic characteristics of the global study population, both the group of women who had never undertaken an induced abortion and the group of women with history of at least one induced abortion. Married women were most represented in the global study population (68.5\%), in those with history of induced abortion (64.9\%) and in those who never aborted (69.8\%). More than the half of the respondents in both the group of women with history of induced abortion (63.3\%) and no history of induced abortion (67.1\%) were students or unemployed women. Ninety eight percent of participants had gone to primary school at least, and 21.2\% had continued school after secondary education.

One hundred and eleven (83\%) cases of induced abortions were carried out in a health facility and 23 (17\%) cases in private homes. Of these, 58 (43.3\%) cases were performed in public health facilities and $53(39.5 \%)$ in private health facilities.

Table 2 shows the distribution of induced abortion with respect to abortion providers, methods of abortion and the rural and urban settings. The Gynaecologists/obstetricians were abortion providers only in 24 (13.2\%) cases of induced abortion. However, they were significantly more represented in urban setting than in rural setting $(20.4 \%$ vs $4.81 \%$; $\mathrm{p}<0.001)$. Medical doctors and nurses were the most frequent abortion providers in urban (84.7\%) and rural setting (77.2\%). Dilatation and curettage was the most use method of induced abortion in rural setting $(66.2 \%$; $\mathrm{p}<0.001)$ while uterine aspiration was the significantly most use method of abortion in urban setting (59.1\%; $\mathrm{p}<0.001)$.

Figure 1 shows the distribution of reasons for induced abortion. the reasons for induced abortions were varied. The three main reasons for induced abortion advanced by the respondents were to pursue their studies (34.3\%), not married (22.6\%) and fear of parental disapproval (13.9\%).

Figure 2 presents the distribution of reported complications of induced abortion. Complications were reported by 27 of the 134 (20\%) women who had undertaken a voluntary induced abortion. Excessive bleeding was the most reported complication (70.4\%). In the present study we could not have the information on maternal death as complication of induced abortion.

Table 1. Socio demographic characteristics of the global study population, women never had induced abortion and women had at least one abortion.

\begin{tabular}{|c|c|c|c|c|c|c|c|}
\hline \multirow{3}{*}{ Variables } & \multirow{2}{*}{\multicolumn{2}{|c|}{$\begin{array}{l}\text { Total study population } \\
\qquad \mathrm{N}=509\end{array}$}} & \multirow{2}{*}{\multicolumn{2}{|c|}{$\begin{array}{l}\begin{array}{c}\text { Women never had induced } \\
\text { abortion }\end{array} \\
\qquad \mathrm{N}=375\end{array}$}} & \multirow{2}{*}{\multicolumn{2}{|c|}{$\begin{array}{l}\text { Women undertaken at least } \\
\text { one induced abortion }\end{array}$}} & \multirow{3}{*}{$P$ value } \\
\hline & & & & & & & \\
\hline & $\mathrm{n}$ & $\%$ & $\mathrm{n}$ & $\%$ & $\mathrm{n}$ & $\%$ & \\
\hline \multicolumn{8}{|l|}{ Marital status } \\
\hline Single & 155 & 30.4 & 111 & 29.6 & 44 & 30.5 & 0.556 \\
\hline Married & 349 & 68.5 & 262 & 69.8 & 87 & 64.9 & 0.343 \\
\hline Others & 5 & 0.9 & 2 & 0.5 & 3 & 2.2 & 0.117 \\
\hline \multicolumn{8}{|l|}{ Profession } \\
\hline Unemployed & 213 & 41.8 & 164 & 43.7 & 49 & 36.5 & 0.180 \\
\hline Employed & 172 & 33.7 & 123 & 32.8 & 49 & 36.5 & 0.180 \\
\hline Student & 124 & 24.3 & 88 & 23.4 & 36 & 26.8 & 0.503 \\
\hline \multicolumn{8}{|c|}{ Level of education } \\
\hline Primary & 128 & 25.1 & 104 & 27.7 & 24 & 17.9 & 0.503 \\
\hline Secondary & 261 & 51.2 & 187 & 49.8 & 74 & 55.2 & 0.335 \\
\hline University & 108 & 21.2 & 73 & 19.4 & 35 & 25.3 & 0.135 \\
\hline None & 12 & 2.3 & 11 & 2.9 & 1 & 0.7 & 0.198 \\
\hline
\end{tabular}


Table 2. Distribution of induced abortion with respect to abortion providers, methods of abortion and the rural and urban setting.

\begin{tabular}{|c|c|c|c|c|c|c|c|}
\hline \multirow{3}{*}{ Variables } & \multirow{2}{*}{\multicolumn{2}{|c|}{$\begin{array}{c}\text { Two settings; } \\
\qquad \mathbf{N}=\mathbf{1 8 1}\end{array}$}} & \multirow{2}{*}{\multicolumn{2}{|c|}{$\begin{array}{l}\text { Urban setting; } \\
\qquad \mathbf{N}=\mathbf{9 8}\end{array}$}} & \multirow{2}{*}{\multicolumn{2}{|c|}{$\begin{array}{c}\text { Rural setting; } \\
\qquad \mathbf{N}=\mathbf{8 3}\end{array}$}} & \multirow{3}{*}{$P$ value } \\
\hline & & & & & & & \\
\hline & $\mathbf{n}$ & $\%$ & $\mathbf{n}$ & $\%$ & $\mathbf{n}$ & $\%$ & \\
\hline \multicolumn{8}{|l|}{ Qualification of abortion } \\
\hline \multicolumn{8}{|l|}{ Providers } \\
\hline Gynecologist/obstetrician & 24 & 13.2 & 20 & 20.40 & 4 & 4.81 & $<0.000$ \\
\hline Others medical doctor & 64 & 35.3 & 32 & 32.65 & 28 & 33.7 & 0.996 \\
\hline Nurse & 60 & 33.1 & 32 & 32.65 & 28 & 33.7 & 0.996 \\
\hline Non health professionals & 33 & 18.2 & 14 & 14.28 & 19 & 22.8 & 0.193 \\
\hline \multicolumn{8}{|c|}{ Methods of induced abortion } \\
\hline Conventional drugs & 22 & 12.1 & 10 & 12.0 & 12 & 14.4 & 0.519 \\
\hline “Traditional” procedures & 22 & 12.1 & 10 & 12.0 & 12 & 14.4 & 0.519 \\
\hline Dilatation and curettage & 75 & 41.4 & 20 & 20.4 & 55 & 66.2 & $<0.000$ \\
\hline Uterine aspiration & 62 & 34.2 & 58 & 59.1 & 4 & 4.8 & $<0.000$ \\
\hline
\end{tabular}

\section{Discussion}

Induced abortion in Cameroon is permitted when a woman's life is at risk, to preserve her physical and mental health and on grounds of rape or incest [2].

Illegality and the immorality of induced abortion, which are at the heart of public abortion polemic, are often taken as the ethical standard [3]. In the present study conducted among women of 15 - 49 years attending obstetrics and gynecology services in urban and rural areas of Cameroon, we founded that globally, $26.5 \%$ women reported to have undertaken at least one previous voluntary induced abortion, $25.6 \%$ in urban area and $27.1 \%$ in rural area. The prevalence of induced abortion in our study is higher than $20 \%$ found by Mosoko et al. in a previous study conducted at Yaoundé in 2004 among women attending antenatal care services [13]. The difference of prevalence in these two studies can be explained by the facts that, Mokoso et al. in their study focused on antenatal care attendees and only abortions between the last birth and that ongoing pregnancy were considered. These results show that despite the illegality and publicly admitted immorality of voluntary induced abortion in Cameroon, a large number of Cameroonian women terminate unwanted pregnancies. It has been estimated that almost two in every five pregnancies worldwide are unplanned as a result of non-use of contraception or of ineffective contraceptive use or method failure [14].

Clandestine induced abortions result in complications, some of which are life threatening [15]. In this study, the overall frequency of complications reported by respondents was $20 \%$. Our result is lower than $59.6 \%$ of complications of induced abortion reported in 2014 by Adanu et al. in Ghana [9]. The lower frequency of induced abortion complications in our study in relation to the Ghanaian study can be explained by the fact that in our study, a large proportion (82.8\%) of induced abortion were carried out in health structures and up to $77.1 \%$ of the abortion providers in Wum, and $85.8 \%$ of those in Yaoundé were health professionals.

In accordance with others authors [7] [9], haemorrhage and infection were the main immediate reported complications in the present study.

When women became pregnant their decision to have an abortion depended heavily on social and economic factors [16]. The main reasons for terminating pregnancy found in our study were fear of losing their educational opportunities, fear of parental disapproval, and not want a pregnancy without being married. Our results are similar to those found in the Ghanaian study and to a previous study conducted in southern Cameroon which reported that abortion is more socially acceptable than pre marital child birth [9] [17].

The wish for privacy and secrecy, along with financial reasons, were key motivations for choosing a provider and an abortion method, which in turn decisively influenced the risk of complications [16].

Surgical methods of abortion (Dilatation and Curettage or uterine aspiration) were reported to be used in $79.6 \%$ 


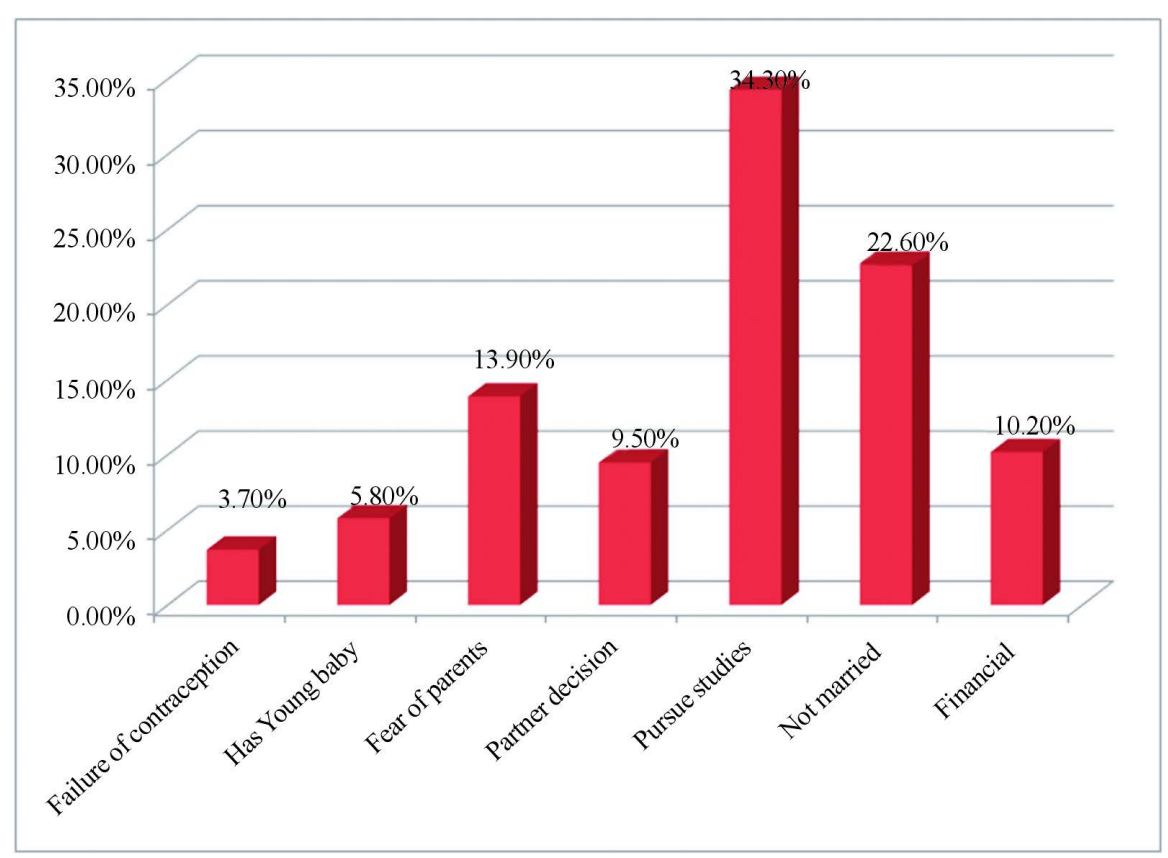

Figure 1. Distribution of reasons for induced abortion.

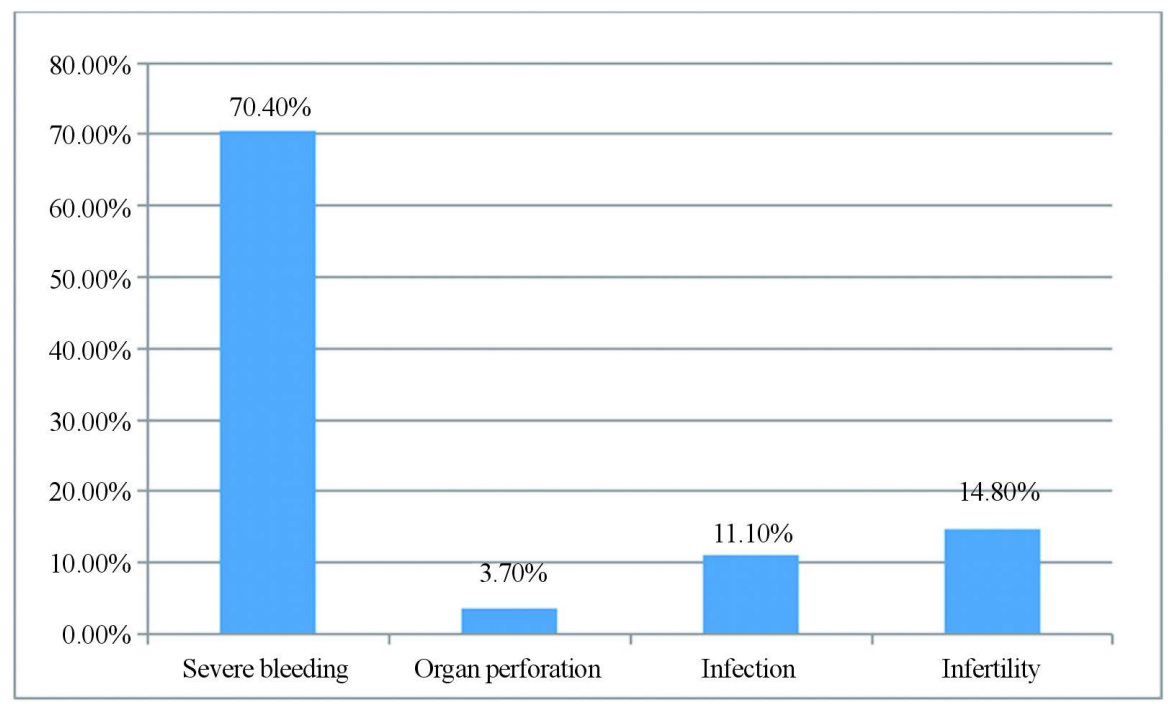

Figure 2. Distribution of reported complications of induced Abortion.

of abortions in Yaoundé and 71\% of abortions in Wum. These results are similar to those found in a Nigerian study where dilatation and curettage and vacuum uterine aspiration were respectively used in $76 \%$ and $72 \%$ of cases [18]. This high frequency of surgical methods of abortion in these two studies can be explain by the large proportion of medical doctors as abortion providers in the two studies. Wonkam and Hurst in 2007 reported that the acceptance of voluntary abortion in Cameroon increases as we move from preclinical medical students, through clinical students to physicians [19]. The present study was hospital population based study which can constitute a selection bias. However, this study was conducted in the most frequented hospitals in these areas, thus the study population will be representative of the population of these regions.

\section{Conclusion}

Despite its illegality in Cameroon, the prevalence of voluntary induced abortion was high (26.3\%) in this study. 
Hemorrhage and sepsis were the most frequently reported complications. The main reasons for abortion were pursuit of studies, not wanting to be pregnant without being married and fear of parents. There is a need to improve prevention of unwanted pregnancies and an access to safe abortion in our setting. This also calls for an improvement in the accessibility of women to contraceptive methods by bringing the contraceptive services closer to women in their social or professional environment and to reinitiate the controversial debate on legal margins of abortion in Cameroon.

\section{References}

[1] Indriso, C. and Mundigo, A.I. (1999) Introduction to Abortion in the Developing World. Zed Books, London, $23-52$.

[2] United Nations (2002) Abortion Policies. A Global Review. Cameroon, 81-82.

[3] Sylvie Schuster, S. (2010) Women's Experiences of the Abortion Law in Cameroon: "What Really Matters". Reproductive Health Matters, 18, 137-144. http://dx.doi.org/10.1016/S0968-8080(10)35503-0

[4] Rosenfield, A. (1994) Abortion and Women's Reproductive Health. International Journal Gynecology and Obstetrics, 46, 173-179. http://dx.doi.org/10.1016/S0020-7292(98)00193-3

[5] Bleek, W. and Asante-Darko, N. (1986) Illegal Abortion in Southern Ghana: Methods, Motives and Consequences. Human Organization, 45, 333-344. http://dx.doi.org/10.17730/humo.45.4.h0322wm00272u23m

[6] Ahman, E. and Shah, I. (2002) Unsafe Abortion: Worldwide Estimates for 2000. Reproductive Health Matters, 10, 1317. http://www.jstor.org/stable/3775768 http://dx.doi.org/10.1016/S0968-8080(02)00012-5

[7] Sangala, V. (2005) Safe Abortion: A Woman’s Right. Tropical Doctor, 35, 130-133. http://dx.doi.org/10.1258/0049475054620743

[8] Bankole, A., Singh, S. and Haas, T. (1998) Reasons Why Women Have Induced Abortions: Evidence from 27 Countries. International Family Planning Perspectives, 24, 117-127. http://dx.doi.org/10.2307/3038208

[9] Adanu, R.M.K., Ntumy, M.N. and Tweneboah, E. (2005) Profile of Women with Abortion Complications in Ghana. Tropical Doctor, 35, 139-142. http://dx.doi.org/10.1258/0049475054620725

[10] Rasch, V., Silberschmidt, M., Mchumvu, Y. and Mmary, V. (2000) Adolescent Girls with Illegally Induced Abortion in Dar es Salaam: The Discrepancy between Sexual Activity and Lack of Access to Contraception. Reproductive Health Matters, 8, 53-62. http://dx.doi.org/10.1016/S0968-8080(00)90006-5

[11] Agadjian, V. (1998) “Quasi-Legal Abortion” Services in a Sub-Saharan Setting: Users’ Profile and Motivations. International Family Planning Perspectives, 24, 111-116. http://dx.doi.org/10.2307/3038207

[12] Ahmed, M.K., Rahman, M. and van Ginneken, J. (1998) Induced Abortion in Matlab, Bangladesh: Trends and Determinants. International Family Planning Perspectives, 24, 128-132. http://dx.doi.org/10.2307/3038209

[13] Mosoko, J.J., Delvaux, T., Glynn, J.R., Zekeng, L., Macauley, I. and Bue, A. (2004) Induced Abortion among Women Attending Antenatal Clinics in Yaoundé, Cameroon. East African Mediterranean Journal, 8, 61-62.

[14] The Alan Guttmacher Institute (1999) Sharing Responsibility: Women, Society and Abortion Worldwide. The Alan Guttmacher Institute, New York.

[15] Lassey, A.T. (1995) Complications of Induced Abortions and Their Preventions in Ghana. East African Medical Journal, 72, 774-777.

[16] Schuster, S. (2005) Abortion in the Moral World of the Cameroon Grassfields. Reproductive Health Matters, 13, 130138. http://dx.doi.org/10.1016/S0968-8080(05)26216-X

[17] Johnson-Hanks, J. (2002) The Lesser Shame: Abortion among Educated Women in Southern Cameroon. Social Science \& Medicine, 44, 1337-1349. http://dx.doi.org/10.1016/S0277-9536(01)00276-3

[18] Henshaw, S.K., Singh, S., Oye-Adeniran, B.A., Adewole, I.F., Iwere N. and Cuca, Y.P. (1998) The Incidence of Induced Abortion in Nigeria. International Family Planning Perspectives, 24, 155-161. http://dx.doi.org/10.2307/2991973

[19] Wonkam, A. and Hurst, S.A. (2007) Acceptance of Abortion by Doctors and Medical Students in Cameroon. The Lancet, 369, 1999. http://dx.doi.org/10.1016/s0140-6736(07)60938-6 